\title{
Coro de cisnes, cantos de sirenas: una aproximación a la música en los monasterios del Chile colonial ${ }^{1}$
}

\section{Swan Choirs, Siren Songs: An Approach to the Music in the Monasteries of Colonial Chile}

\author{
por \\ Alejandro Vera \\ Instituto de Música, Pontificia Universidad Católica de Chile, Chile \\ averaa@uc.cl
}

El presente trabajo explora por vez primera la práctica musical en los monasterios de monjas del Chile colonial. Partiendo de la información inédita recopilada en el archivo del Monasterio de La Victoria de Santiago, se analizan aspectos históricos y musicales tales como la imagen de la monja música en la historiografía tradicional y postmoderna; su estatus social en el período colonial; la evolución de las plantillas musicales (instrumentistas y cantoras), con sus correspondientes cambios estilísticos y la injerencia que tenían los músicos ajenos al monasterio. Por último, se cuestiona la supuesta independencia de género de las monjas y se plantea la hipótesis de que las repetidas censuras a sus prácticas artístico-musicales estuvieron motivadas no sólo por propósitos moralizantes, sino también por la necesidad del clero secular y la autoridad civil de limitar el crecimiento de las instituciones monásticas.

Palabras clave: Música, Chile, Colonia, monjas, monasterios, instrumentistas, cantoras, estatus social, autoridad masculina, clero secular, clero regular.

This is the first study about the musical practice in convents of Colonial Chile on the basis of new data collected in the archive of the convent of La Victoria in Santiago. It considers historical and musical aspects such as the image of the nun musician in traditional and postmodern historiography, her social status during the colonial period, the evolution of music groups (instrumentalists and singers), the stylistic changes associated with them, and the role played by foreign male musicians in the monastery. Finally, it questions the assumption that nun musicians enjoyed an independence from masculine gender. Furthermore it puts forward as a hypothesis that the frequent prohibitions of their musical and artistic practices originated not only in moralistic purposes, but also in the need of the secular clergy and civic authorities of limiting the growth of monastic institutions.

Keywords Music, Chile, Colony, nun, convents, instrumentalists, singers, social status, masculine authority, secular clergy, regular clergy.

\footnotetext{
${ }^{1}$ Una versión preliminar de este trabajo fue presentada en el IV Congreso de la Sociedad Chilena de Musicología, Santiago, Instituto Profesional Escuela Moderna de Música, 12-01-2007. La versión definitiva es resultado del proyecto FONDECYT 1071121. Agradezco al archivero de San Francisco, padre Rigoberto Iturriaga, y a las religiosas del Monasterio de La Victoria por las facilidades brindadas durante mi investigación.
} 


\section{INTRODUCGIÓN}

“Coro de cisnes...”. Con este título el Padre Juan de Guernica presentó, en un breve apartado de tres páginas, interesantes datos sobre la práctica musical en el monasterio de clarisas de La Victoria de Santiago, como parte de su libro sobre esta institución publicado en $1944^{2}$. El autor ofreció noticias de varias monjas músicas que ingresaron en el monasterio ${ }^{3}$ por su oficio de cantoras o instrumentistas, percatándose de que eran liberadas, íntegra o parcialmente, de pagar la jugosa dote de entrada. Asimismo, situó a la música entre las disciplinas enseñadas por las monjas a las niñas que estaban bajo su cuidado y relacionó su presencia con las necesidades del culto divino y la recreación de las religiosas.

A pesar de su importancia, hasta el momento ningún musicólogo había prestado atención a los datos ofrecidos por Guernica, con excepción de un par de monjas mencionadas por Pereira Salas en un artículo de 1945, de tan sólo una página y sin bibliografía ${ }^{4}$. Esto puede relacionarse con el poco interés que, hasta una época reciente, ha mostrado la musicología chilena por el período colonial, sin duda por los prejuicios heredados del nacionalismo decimonónico ${ }^{5}$. Además, el libro de Guernica fue publicado con posterioridad a Los orígenes del arte musical de Pereira Salas ${ }^{6}$, que durante medio siglo constituyó prácticamente la única fuente para todo lo que se decía en relación con la música de la colonia. Los aportes de Guernica fueron recogidos, en cambio, por la historiografía feminista, pero sin que sus autoras profundizaran en aspectos musicales ${ }^{7}$.

Frente a este magro panorama, el estudio de la música en los monasterios ha contribuido en las últimas décadas a renovar la musicología europea y latinoamericana, permitiendo conocer el papel que desempeñaron sujetos que tradicionalmente ocupaban un lugar marginal en la historia de la música -principalmente la mujer, pero también niñas, criados(as), esclavos(as) - y llevando los estudios sobre instituciones religiosas desde las catedrales hacia otras circundantes (monasterios, parroquias y beaterios), en una perspectiva descentralizadora. Lo más sorprendente ha sido constatar que estas últimas, consideradas tradicionalmente como instituciones menores o periféricas, tenían en ocasiones una actividad musical equivalente o incluso superior a la de las catedrales, dada su mayor identificación con las elites locales (criollas) y su flexibilidad para incorporar músicos afrodescendientes ${ }^{8}$.

Lo anterior justifica que en este trabajo se intente una primera aproximación al tema de la música y las monjas en el Chile colonial, partiendo de una institución concreta -el Monasterio de La Victoria, fundado en 1678- para incluir luego consideraciones sobre otros centros. La información presentada aquí ha sido ob-

\footnotetext{
${ }^{2}$ Guernica 1944: 93-95. Véase también la tabla complementaria en las pp. 704-765.

${ }^{3}$ En este trabajo utilizo el término exclusivamente para referirme a las instituciones femeninas y no a los conventos de frailes.

${ }^{4}$ Pereira Salas 1945.

${ }^{5}$ Vera 2006 y Vera 2010 (en prensa).

${ }^{6}$ Pereira Salas 1941.

${ }^{7}$ Por ejemplo, en Iglesias 1999 y Salinas 1994: 163-165.

${ }^{8}$ Véanse, entre otros, Lange 1986; Cadenas 2002; Aguirre 2004; Vera 2004; Baker 2008.
} 
tenida del archivo del monasterio y amplía de forma importante los aportes de Guernica, pero será complementada con datos del Archivo Nacional y el Archivo Histórico del Arzobispado de Santiago, aparte de la bibliografía pertinente. Por las limitaciones de espacio me es imposible presentar un panorama general de la vida musical monástica, pero estimo que los aspectos tocados en las páginas que siguen son suficientes para mostrar su riqueza y complejidad.

\section{LAS MONJAS MÚSICAS (DE LA VICTORIA)}

En líneas generales, podemos decir que la monja música en la historiografía tradicional era una figura casi inexistente, pero cuando se aludía a ella solía pintársele como una mujer devota, dedicada a la liturgia y a lo más entretenida de vez en cuando en sanas recreaciones, que incluían el canto de coplas, siempre a lo divino. La metáfora del cisne empleada por Guernica busca claramente representar la serenidad, elegancia y nobleza que tradicionalmente se esperaba de una monja colonial, sin olvidar la analogía existente entre la resignación cristiana y aquella antigua leyenda que pinta al cisne como un animal que canta incluso en el momento previo a su muerte ${ }^{9}$.

La musicología postmoderna ha intentado mostrar una faceta muy diferente. No es casual que en una época más reciente la metáfora del cisne haya sido reemplazada por la de una sirena ${ }^{10}$, con todas las connotaciones eróticas que este ser mitológico tiene a lo largo de la historia. La monja posmoderna, como podríamos llamarla, es transgresora e interpreta canciones profanas para deleite de los aficionados que asisten a escucharla. Estos últimos, según veremos, se permiten incluso cortejarla a horas inapropiadas. Además, suele ser astuta y cultivada, mucho más que su equivalente seglar, sumisa hasta más no poder ante sus padres y marido. Santa Teresa de Jesús en su faceta menos contemplativa y, sobre todo, Sor Juana Inés de la Cruz constituyen sus modelos, sin olvidar a nuestra beligerante Úrsula Suárez, quien, al parecer, no llegó a desempeñar del todo el oficio musical (vicaria de coro) que se le había encomendado en La Victoria y es más conocida por las sabrosas anécdotas y "travesuras" contenidas en su Relación autobiográfica escrita a comienzos del siglo XVIII ${ }^{11}$. Para qué hablar de Catalina de Erauso, mitad monja/mitad alférez que, sin ser música, contribuye a la construcción de la monja postmoderna con una apropiada ambigüedad ${ }^{12}$.

El lector se estará preguntando cuál de las dos es la imagen más adecuada para las monjas de la época, especialmente las del Chile colonial. Quizás la pregunta correcta sea más bien qué razón hay para escoger entre una y otra. Después de todo, tanto la imagen casta como la transgresora conviven ya en muchas crónicas de los siglos XVII y XVIII. Se trata, en otras palabras, de comprender que el monasterio constituía un espacio para prácticas e identidades contradictorias, las cuales, a

${ }^{9}$ Arnott 1977: 149-150.

${ }^{10}$ Kendrick 1996: 95, 140.

11 Suárez 1984: 257.

${ }^{12}$ De los escritos históricos y de ficción dedicados a ella, véase Gallardo 2005, que combina ambas esferas. 
pesar de ello, coexistían en una relativa armonía. Según veremos, algunas monjas encontraron en la música profana una fuente de placer e incluso una vía para el lucimiento personal ante un auditorio predominantemente masculino. No obstante, esto no implica que su devoción religiosa fuese fingida, tal como otras utilizaron la música como un medio para salir de la pobreza, lo que no quiere decir que no sintiesen un gusto personal o incluso una auténtica vocación por ella.

Este último ejemplo nos permite entrar en materia, pues la monja música de La Victoria era ante todo pobre, o al menos no solía pertenecer a los estratos altos de la sociedad. De las treinta y seis que he identificado en los libros de peticiones y otras fuentes, la mayor parte (dos tercios según los datos del apéndice) ingresa como monja de velo blanco, categoría destinada a aquellas que tenían un estatus social inferior y pagaban una dote aproximada de 800 pesos. Estas monjas desempeñaban oficios domésticos como los de cocinera u hornera, y ninguna de las que ingresaron como músicas pagó dote alguna. Esto demuestra a la vez su precaria condición económica y la importancia asignada a los conocimientos musicales en el monasterio. De las monjas músicas que ingresaron con la categoría de velo negro, en cambio, sólo un $45 \%$ fue liberado de la dote (1600 pesos), mientras que el $55 \%$ restante pagó una cantidad parcial que variaba, al parecer, de acuerdo a las necesidades musicales del monasterio y otros aspectos.

Aunque pudiera cuestionarse si la pobreza señalada por las candidatas era efectiva o representaba más bien un pretexto para ahorrarse el dinero de la dote, el caso de las monjas de velo blanco, al menos, parece confiable, pues si una joven tenía los 800 pesos o una cantidad similar lo más lógico era que la pagase y, con su oficio musical como complemento, postulase al velo negro. Éste fue el caso de Manuela Infante, quien fue admitida en 1806-1808 en esta categoría por solo 500 pesos, más su oficio de cantora. Así también María de la Concepción Carrasco ingresó en 1792-1794 como cantora de velo blanco, pero con la opción de acceder al velo negro si conseguía reunir 500 pesos de dote ${ }^{13}$.

La precariedad económica de estas monjas queda también de manifiesto en sus propios testimonios. Muchas de ellas afirman que fueron acogidas en el monasterio por caridad y se dedicaron al estudio de un instrumento por no tener dinero para pagar la dote. Es el caso, entre otras, de Catalina Soto en 1744, Isabel Muñoz en 1752, y las hermanas Rosa y Francisca Zumarán en 1752, según consta en los libros de peticiones. La primera de ellas decía: "siendo mi pobreza suma, he procurado para conseguir el estado de religiosa de velo blanco en dicho convento habilitarme en el instrumento del violín"14. A pesar de ello, la arpista Josefa Soto nos muestra que la música no era sólo un medio para tomar el estado religioso, sino también un elemento de goce al que se accedía por inclinación personal. En 1776 pide entrar como monja de velo blanco y "ser también admitida con el dulce reato pensional de la música, designios ambos que he elegido para el logro de mi vocación..."

${ }^{13}$ Archivo del Monasterio de La Victoria (en adelante AMV), "Peticiones de religiosas de coro 1800-1850", expediente 6; y "Peticiones de religiosas legas 1700-1800", expediente 57.

${ }^{14} \mathrm{AMV}$, "Peticiones de religiosas legas 1700-1800", expediente 13.

${ }^{15}$ Ibid., expediente 45 . Las cursivas son mías. 
Todo esto debería llevarnos a revisar, al menos en parte, la idea presente en estudios anteriores del arpa colonial como un instrumento de elite ${ }^{16}$. Si, como se ve en el apéndice, las arpistas que ingresaron en el monasterio no pagaron en general dote alguna, podemos dudar de que el manejo de este instrumento constituyera un símbolo de estatus al interior de la institución.

A través de los libros de peticiones y otros documentos podemos comprobar que los conocimientos musicales de algunas monjas no dependían sólo de la formación recibida en el monasterio o su talento individual. Ana Josefa Rodríguez Cañol, arpista y cantora que profesó en $1769^{17}$, era hermana de Pedro Antonio y Manuel Rodríguez Cañol, sochantres de la catedral de Santiago durante el siglo $\mathrm{XVIII}^{18}$. Es muy probable además que su padre, Juan Antonio Rodríguez Cañol, y el organista y cantor de la catedral Juan Antonio Cañol ${ }^{19}$ fuesen la misma persona. Asimismo, las hermanas Zumarán mencionadas anteriormente eran sobrinas de Isabel Pinto Arancibia, instrumentista, cantora y maestra de música ${ }^{20}$. Por lo tanto, hubo ciertas familias formadas por músicos profesionales y otras que favorecieron especialmente el cultivo de la música entre sus miembros por considerarla una bella y digna afición.

En este punto, es necesario recordar que muchas niñas eran ingresadas por sus padres en los monasterios no para hacerse religiosas, sino para formarse y luego reintegrarse en sociedad ${ }^{21}$. Por ejemplo, Josefa Dolores Peñailillo fue ingresada en 1747 en el beaterio de Santa Rosa para que aprendiese música, según ella misma declara. Finalmente se inclinó por el estado religioso. No obstante, esto demuestra que el conocimiento musical constituía un atributo importante para la mujer de la época en los círculos aristocráticos y no sólo un medio para entrar en el claustro ${ }^{22}$. Como vemos, la documentación religiosa puede ofrecer información relevante acerca del ámbito privado.

\section{PRÁCTICAS Y OFICIOS MUSICALES EN EL MONASTERIO}

Como ocurre en muchos ámbitos del Chile colonial, no he localizado partituras de la época en el monasterio. Pero esto no debe llevarnos a pensar que no hubo una tradición de música escrita, idea de corte positivista que, no obstante, ha estado presente durante bastante tiempo en la musicología chilena ${ }^{23}$. En este trabajo asumimos el desafío de imaginar la música de la institución y sus intérpretes, en base a la información documental e histórica localizada.

${ }^{16}$ Fahrenkrog 2006: 75-80.

${ }^{17}$ AMV, "Peticiones de religiosas de coro 1700-1799", expediente 46.

${ }^{18}$ El parentesco se confirma en Archivo Nacional Histórico, Escribanos de Santiago, vol. 711, fol. 282, y Judicial de Santiago, Civiles, legajo 212, pieza 8, fol. 2v.

${ }^{19}$ Véase sobre este músico Archivo Histórico del Arzobispado de Santiago, Secretaría, vol. 23, fol. 24; y Archivo de la Catedral de Santiago, Acuerdos del cabildo, vol. 2, fol. 104v.

${ }^{20} \mathrm{AMV}$, "Escritos antiguos", documento de 03-03-1780 (consta su parentesco con Rosa Zumarán).

${ }^{21}$ Cano Roldán 1981: 309.

${ }^{22}$ [Jesús] 1923: 170 y Medina 1906: 660.

23Vera 2006: 153. 
Las treinta y cinco monjas músicas listadas en el apéndice constituyen un número apreciable si consideramos que la cifra real debió ser bastante mayor, tanto por la naturaleza fragmentaria de los documentos como porque el coro se veía frecuentemente ampliado por mujeres laicas. Por ejemplo, Juana Álvarez, al momento de tomar el hábito en 1736, indica que desde los once años cantaba en el coro del monasterio. En 1767, en apoyo de la solicitud de ingreso de la arpista Mercedes Tristán, la abadesa señala que por no haber ninguna religiosa que ejecute el arpa "de seculares se sirve el coro: éstas son las que llevan el peso todo el año en fiestas y funciones de comunidad", la propia Tristán, de hecho, había comenzado a aprender este instrumento a los diez años y al momento de su ingreso en el noviciado llevaba ya una década sirviendo como arpista ${ }^{24}$. Por lo tanto, estas intérpretes laicas o "seculares" eran por lo general niñas y jóvenes que se criaban en el claustro al amparo de las monjas.

En otros monasterios latinoamericanos podían integrarse al cuerpo de músicas algunas criadas o incluso esclavas de las muchas que solían vivir en estas instituciones ${ }^{25}$. Aunque no he encontrado datos claros al respecto, es posible que fuese una criada una tal Rosita Porras que recibió en 1733 "una arroba y veinte libras de azúcar" en pago "por su asistencia en todo el año tocando en el coro" 26. En cuanto a los afrodescendientes, el único documento que los vincula con la música proviene de la fiesta de Santa Clara que las monjas celebraron en 1678, cuando se dieron 10 reales "a los negros cajeros y al trompeta que tocaron la víspera y el día que se hizo la fiesta”. Pero éstos no necesariamente eran esclavos del monasterio, sino probablemente músicos independientes que prestaban servicios ocasionales en diversas iglesias de la ciudad. Una semana después, el 21 de agosto de 1678, se pagaron " 4 reales a cuatro negros que llevaron el órgano al hospital" 27 , lo que no implica que fuesen músicos. Aun así el testimonio es interesante porque sugiere que el hospital de San Juan de Dios había facilitado dicho instrumento a las monjas para que pudiesen celebrar con solemnidad su primera fiesta de Santa Clara, denotando los estrechos vínculos que existían entre las instituciones religiosas de la época.

La tabla del apéndice muestra un claro predominio de las instrumentistas sobre las cantoras, lo que indica que el manejo de un instrumento constituía la cualidad más valorada entre las monjas, quizás por ser más escasa. Los instrumentos que se mencionan son, en orden de preferencia, el arpa, el violín y el órgano, aunque es obvio que las "organistas" ejecutarían igualmente el clave. De hecho, aunque no aparezca ninguna "clavecinista" en los documentos, sor Isabel Pinto dejó en 1780 un "clave de cuatro órdenes" al monasterio, señalando que era el mejor que había en Santiago, y hacia 1803 Teresa Quesada ofreció un clave como parte de su dote ${ }^{28}$. Lo que la tabla no indica es que algunas de estas monjas llegaron a ocupar el puesto de vicaria de coro, que representaba la máxima autoridad en

${ }^{24}$ AMV, "Peticiones de religiosas legas 1700-1800", expedientes 8 y 36, ambos sin foliar.

${ }^{25}$ Cadenas 2002: 30-31.

${ }^{26}$ AMV, Libro de gastos 1713-1738, fol. 46v (segunda sección).

${ }^{27}$ AMV, Libro de gastos 1678-1697, fol. 7 .

${ }^{28}$ La referencia a Pinto consta en Guernica 1944: 147-148 y AMV, "Escritos antiguos 1682 al 1844". Sobre Quesada véase AMV, "Peticiones de religiosas de coro 1800-1850", expediente 3. 
el plano musical. Hemos visto que el oficio fue encargado a nuestra querida Úrsula Suárez en los primeros años, aunque no esté del todo claro hasta qué punto lo ejerció. En la segunda mitad del siglo XVIII encontramos repartida esta responsabilidad en dos puestos, la vicaria de coro y la maestra de música, división análoga al parecer a la de vicaria de coro y maestra de capilla que encontramos en otro monasterio latinoamericano ${ }^{29}$. La primera se ocuparía pues del canto llano y el buen desarrollo de la liturgia diaria, mientras que la segunda dirigiría la polifonía e instruiría a las cantoras e instrumentistas. Hacia 1776 ocupaban dichos cargos, respectivamente, Faustina Valdovinos e Isabel Pinto Arancibia ${ }^{30}$.

El ingreso de violinistas hacia 1750 refleja la introducción del estilo italianizante, con su formato tipo de dos partes obligadas para este instrumento y un bajo continuo, que caracteriza a la mayoría de las partituras del siglo XVIII conservadas en los archivos coloniales hispanoamericanos. Los instrumentos armónicos, como el arpa, el órgano y el clave, ejecutarían pues el bajo y su correspondiente relleno armónico o "acompañamiento". El testimonio de Marta de los Santos Tobar, quien en 1782 se comprometió a ejecutar el canto llano "en el coro alto y bajo"31, sugiere además que las cantoras e instrumentistas pudieron dividirse en dos coros, quizás uno de solistas y otro de ripieno como ocurre en muchas partituras de la época conservadas en la Catedral de Santiago. En ese caso, no es aventurado imaginar que el arpa y el órgano quedasen adscritos a coros distintos, práctica de la que existen indicios tanto en España ${ }^{32}$ como en la pintura colonial cuzqueña o potosina (figura 1), aunque en ambos casos provengan del siglo XVII.

La plantilla instrumental de arpa, violín y teclados (órgano o clave) no era exclusiva de La Victoria. El 25 de junio de 1787 el obispo Alday promulgó un decreto para limitar el número de religiosas de velo blanco en el monasterio de las agustinas, ordenando que no se admitiesen más de ocho cantoras, tres arpistas, tres violinistas y dos organistas ${ }^{33}$. Este documento es importante por dos razones. Primero, denota la importante actividad musical de las agustinas en la época y, segundo, confirma que el monasterio de La Victoria refleja hasta cierto punto las prácticas musicales de otras instituciones similares, lo que justifica el que hayamos enfocado este trabajo como un estudio de caso.

En cuanto a las cantoras, además de una bella voz, una de las cualidades más valoradas en ellas era la capacidad para leer música, como prueba el hecho de que la amplia mayoría manifieste conocer la "solfa" -es decir, la notación musical- y que muchos de los exámenes realizados a las candidatas -algunos de los cuales serán citados más adelante- especifiquen que estaban capacitadas para leer su partitura ${ }^{34}$. Lamentablemente, la documentación no precisa los registros voca-

${ }^{29}$ Cadenas 2002: 31 .

${ }^{30} \mathrm{AMV}$, "Peticiones de religiosas legas 1700-1800", expediente 45.

${ }^{31}$ AMV, "Peticiones de religiosas de coro 1700-1799", expediente 52.

${ }^{32}$ López-Calo 1988: 32-33.

${ }^{33}$ Archivo Histórico del Arzobispado de Santiago, Secretaría, vol. 23, fol. 120. Cf. Cano Roldán 1981: 528 .

${ }^{34}$ Por ejemplo, en 1768 el maestro de capilla Francisco Antonio Silva afirmaba que la arpista Antonia Figueroa aún debía mejorar en su instrumento, pero podía "com gran facilidad em breve tiempo tocar su papel" -AMV, "Peticiones de religiosas legas 1700-1800", expediente 37. 


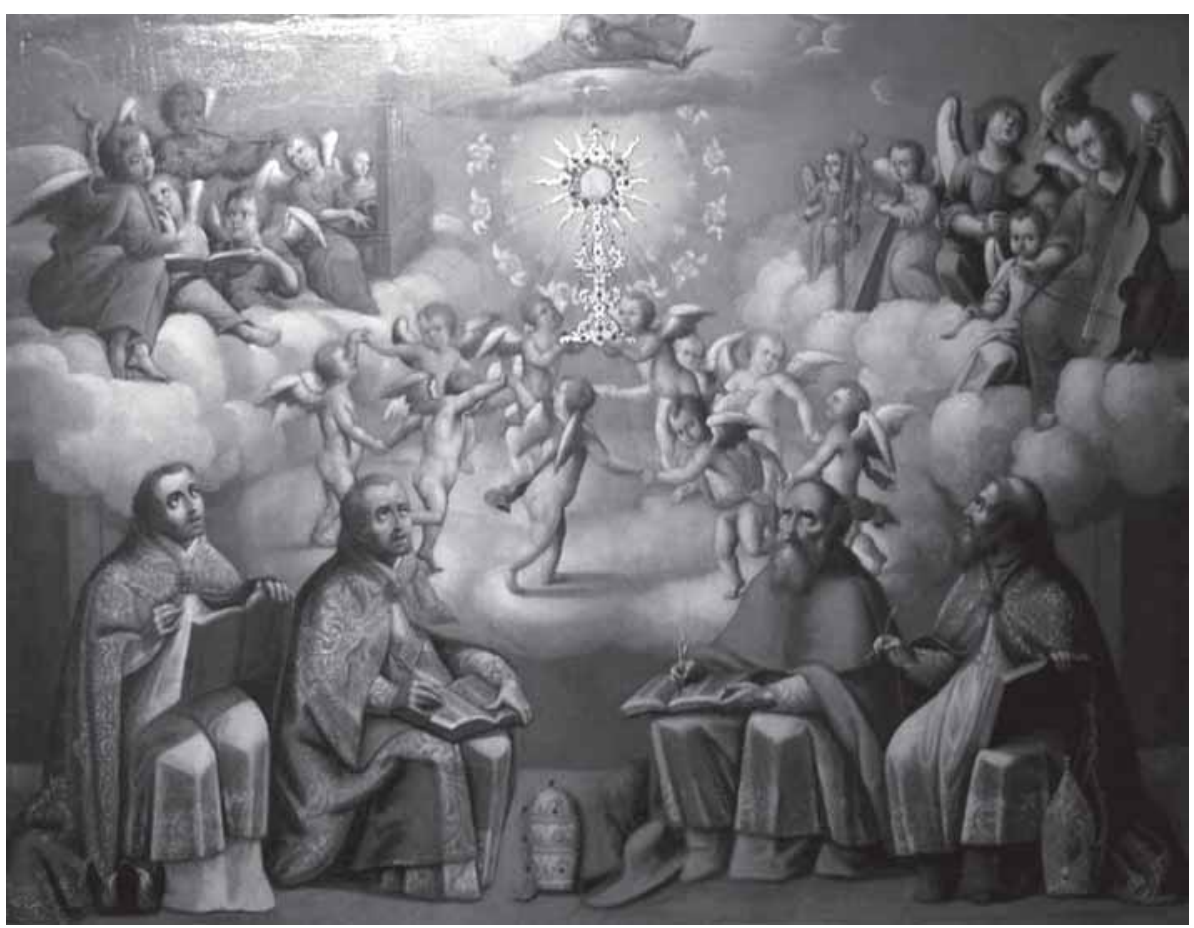

Figura 1: Escuela Potosina, anónimo ca. 1680.

les de cada monja, como sí ocurre en los conventos limeños. A modo de ejemplo, en 1629 Úrsula de Molina, descendiente de los fundadores de Chile, solicitó su ingreso en el monasterio de La Concepción de Lima por tener una "linda voz de tenor, que no hay otra de su metal en el convento..." "35. Pero es obvio que estarían divididas en los registros femeninos tradicionales (soprano, mezzo, contralto) y quizás alguna incursionara en "profundidades" como su similar de Lima.

Por otro lado, es interesante constatar que el canto llano no sólo se acompañaba con órgano, de lo cual hay suficientes pruebas en Chile e Hispanoamérica, sino también con el arpa, como lo muestra el citado testimonio de la arpista Marta de los Santos Tobar, quien se comprometió "a tocar en el Coro en las funciones diarias de canto llano". En consecuencia, este estilo de música debe haberse acompañado de un modo más variado y hasta "colorístico" que el que acostumbramos atribuirle hoy en día, quizás similar al que se empleaba para acompañar la polifonía.

Por último, llama la atención la ausencia de instrumentistas de viento. Se trata de un aspecto interesante porque establece una clara diferencia de género, dado que en las iglesias chilenas los hombres ejecutaban chirimías, bajones y otros similares. Parece pues que los vientos eran considerados poco apropiados al género feme-

${ }^{35}$ Archivo Arzobispal de Lima, Serie Monasterio de la Concepción, signatura IV: 9 (1628/1629). Agradezco esta referencia a Víctor Rondón. 
nino. De hecho, a comienzos del siglo XIX Amasa Délano señalaba a propósito de su paso por Chile que las damas tocaban muy bien la guitarra para acompañar sus voces y que eran muy comunes el arpa, el clave y el pianoforte; en cambio, "los caballeros" tocaban "la flauta y el clarinete" 36 . Otra explicación sería que, dada la asociación en las iglesias coloniales entre los instrumentos de viento y los sectores subalternos de la sociedad (indígenas y afrodescendientes), éstos fuesen ejecutados en los monasterios por las criadas y/o esclavas, como al parecer ocurría en Cuzco ${ }^{37}$. Sin embargo, no tenemos indicios de que esto ocurriese en Chile.

\section{EL CONTROL MASCULINO}

La historiografía feminista ha afirmado con frecuencia que un monasterio constituía un refugio en el que la mujer podía desarrollar inquietudes intelectuales y artísticas que en el exterior le estaban vedadas, por tratarse de "un ámbito aislado y a salvo del control social y autoridad masculina"38. Ha reproducido así, al menos en este aspecto, el tópico del monasterio como isla que caracterizó a gran parte de la historiografía tradicional. El presente apartado está destinado a matizar dicha afirmación.

En rigor, la actividad musical de La Victoria no fue ajena a la intervención masculina. Esta se dio al menos de tres formas: mediante la contratación de maestros de música para enseñar a las monjas, por la necesidad ocasional de contratar organeros, y, sobre todo, por la autoridad que tenían el maestro de capilla y otros músicos para avalar o no la preparación musical de las candidatas.

La contratación de maestros de música comienza casi con la fundación del monasterio. Desde 1679 hasta la década de 1690 figura en los libros de cuentas el "indio cuzco" Gaspar Bartolomé Domínguez, como encargado de enseñar el canto a las monjas y niñas ${ }^{39}$. En el siglo XVIII, consta que el mercedario Francisco Marieluz, venido de Lima, enseñó el arpa a Mercedes Tristán (1767) y Antonia Figueroa (1768), además el órgano a Josefa Tagle (1744) y Josefa Alarcón (1768) ${ }^{40}$. En vísperas de la independencia, en 1807, Josefa Ortúzar afirmaba que el maestro de capilla José de Campderrós le había enseñado la solfa gratuitamente ${ }^{41}$. Por lo tanto, y sin negar el importante rol formador de la vicaria de coro o la maestra de música, es un hecho que una parte de la instrucción musical de las religiosas era proporcionada por hombres.

${ }^{36}$ Citado por Pereira Salas 1941: 44.

${ }^{37}$ Baker 2008: 124.

${ }^{38}$ Salinas 1994: 157 .

${ }^{39}$ AMV, Libro de gastos 1678-1697.

${ }^{40}$ AMV, "Peticiones de religiosas legas 1700-1800", expedientes 36, 37 y 38; "Peticiones de religiosas de coro 1700-1799", expediente 20. Sobre Marieluz, que sin duda corresponde al "mercedario Madux" citado por Pereira Salas, véase Vera 2005: 18-19.

41 “... habiendo desde mis tiernos años deseado el estado de religiosa para mejor servir a Dios, logré por su misericordia que el Sr. Don José de Campderrós llevado de caridad (para que de ese modo pudiese lograr mis deseos) me enseñara la solfa, en la que estoy enterada, como se verá por la certificación que está pronto a dar..."-AMV, "Peticiones de religiosas legas 1801-1900", expediente de Josefa Ortúzar (sin numerar). 
En cuanto a la presencia de organeros, el único testimonio que he encontrado es la contratación de un tal Andrés de Segovia, en 1781, para reparar el órgano del monasterio y entregarlo con seis registros y el "flautaje corriente" nuevo ${ }^{42}$. Con anterioridad, es probable que el mercedario Marieluz se encargase de estas reparaciones, e incluso que él mismo construyese dicho instrumento, pues sabemos que hacia 1757 estaba fabricando un gran órgano para el convento de La Merced de Santiago ${ }^{43}$.

Pero el control masculino se aprecia con mayor claridad en el hecho de que las candidatas fuesen con frecuencia examinadas por músicos ajenos al monasterio. Eran ellos quienes determinaban si sus aptitudes musicales eran las adecuadas, y legitimaban, al fin y al cabo, la condición de "música" de muchas de las monjas. Esta tarea era normalmente encargada por el obispo al maestro de capi1la. De este modo, Francisco Antonio Silva examinó a la cantora Ana Rodríguez Cañol en 1769, la arpista Antonia Figueroa hacia 1770, la organista María del Carmen Mesía en 1778 y 1780, las violinistas y cantoras Ana María de Aguirre y Francisca Javiera Rocha en 1780 y la violinista María Josefa Durán en marzo de $1789^{44}$. Asimismo, José de Campderrós examinó a la cantora Manuela de la Cruz Infante en $1806^{45}$. Aparte de los maestros de capilla, el mercedario Marieluz certificó la competencia musical de la organista Francisca Zumarán en 1756, la cantora y arpista María Mercedes Tristán en 1767 y 1769, y la organista Josefa Alarcón en 1768. Por su parte, José Antonio González examinó a la cantora Juana Carrión en $1803^{46}$. Como es sabido, González era en ese momento organista de la Catedral de Santiago y en 1812 reemplazaría a Campderrós en el puesto de maestro de capilla ${ }^{47}$. El espacio asignado me impide dar cuenta detallada de estos informes, algunos muy interesantes. Pero vale la pena destacar el informe que realizó José de Campderrós en 1806, pues constituye su único documento autógrafo encontrado hasta ahora y demuestra que aún se hallaba activo por aquellos años. La claridad de la imagen hace innecesaria una transcripción (figura 2).

Asimismo, es muy interesante el testimonio de la arpista Josefa Soto en 1766:

"y de [1] aprovechamiento de mi profesión es testigo ocular el Maestro de Capilla [Francisco Antonio Silva] de esta Santa Iglesia Catedral, quien con el motivo de acompañar la música en la festividad próxime [sic] pasada de la seráfica Madre Santa Clara entró a tocar al Monasterio, y en la repetición de aquellos actos formó pleno concepto de mi inteligencia de que hizo un elogio que tal vez no merecería; pero es innegable la

\footnotetext{
${ }^{42}$ AMV, "Escritos antiguos 1682 al 1844", sin foliar. Cabe señalar que la abreviatura de su nombre no es muy clara: podría ser también "Antonio".

${ }^{43}$ Vera 2004: 41.

${ }^{44}$ AMV, "Peticiones de religiosas legas 1700-1800", expedientes 37, 47, 48 y 54; y "Peticiones de religiosas de coro 1700-1799", expedientes 46 y 51.

${ }^{45} \mathrm{AMV}$, "Peticiones de religiosas de coro 1800-1850", expediente 6.

${ }^{46} \mathrm{AMV}$, "Peticiones de religiosas de coro 1700-1799", expediente 28; "Peticiones de religiosas legas 1700-1800", expedientes 36 y 38; y "Peticiones de religiosas legas 1801-1900", expediente 3.

${ }^{47}$ Claro Valdés 1979: 11. Sin embargo, Campderrós no murió en 1812 sino en marzo de 1811 , como se demuestra en Vera 2005: 25.
} 


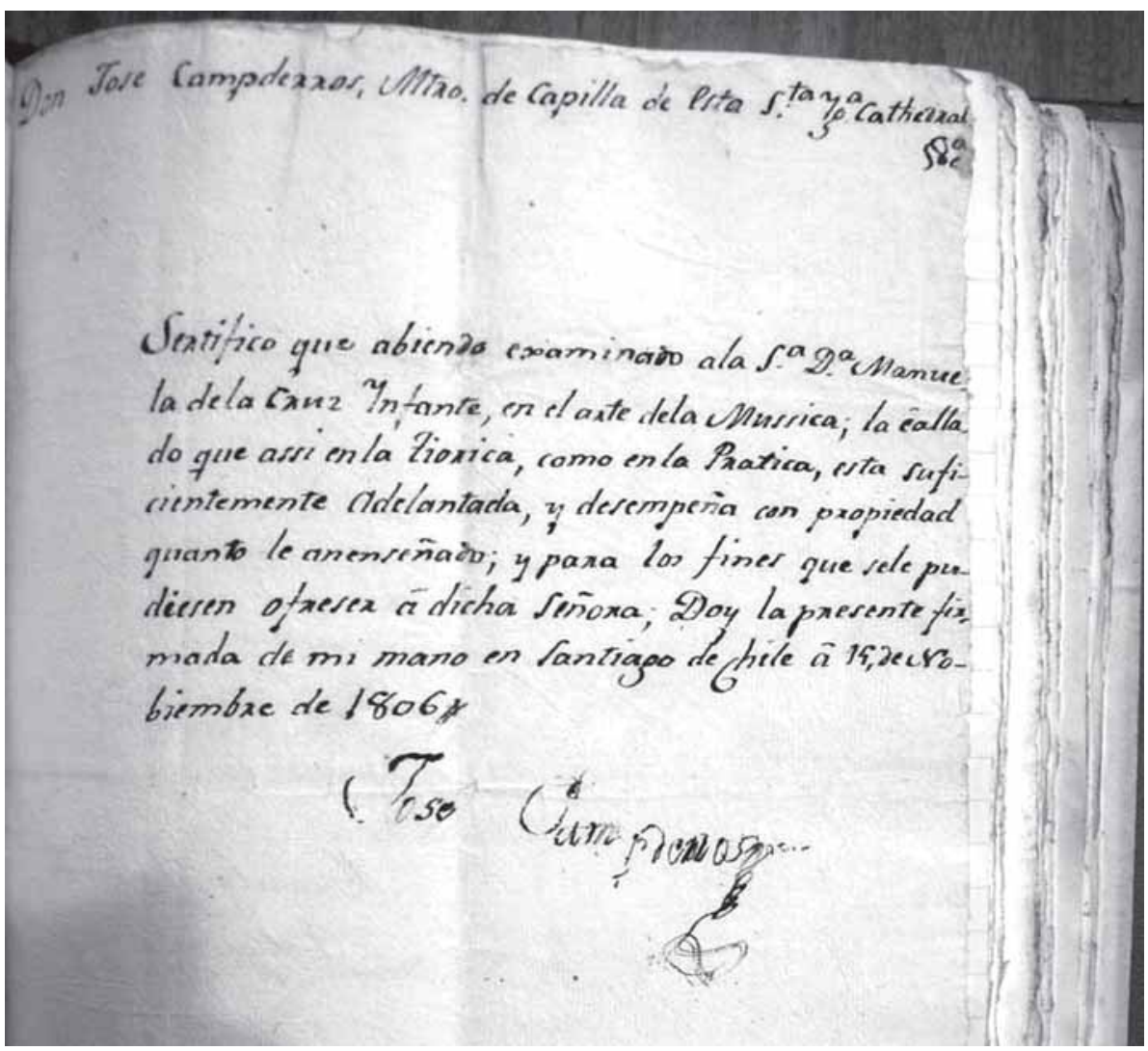

Figura 2: informe de José de Campderrós.

secuela de mi servicio, y que establemente lo he desempeñado desde antes del cumplimiento de doce años hasta el de los veinte..." 48 .

El párrafo anterior deja muy en claro la autoridad musical que las monjas conferían al maestro de capilla y cómo ésta legitimaba su habilidad y preparación como cantoras o instrumentistas. Por lo tanto, si bien no puede negarse que las religiosas tuvieron una mayor independencia de género que sus equivalentes laicas, no eran totalmente ajenas al control masculino; algo que, por lo demás, confirma que los monasterios estaban en permanente vínculo con su entorno.

\section{CENSURAS Y FINANCIAMIENTO MUSICAL}

Es probable que el lector se esté preguntando qué tienen que ver las censuras con el financiamiento de la actividad musical en los monasterios. El presente apartado plantea, justamente, la hipótesis de que ambos aspectos en apariencia

${ }^{48}$ AMV, "Peticiones de religiosas legas 1700-1800", expediente 45. 
desvinculados tenían en realidad una estrecha dependencia, aunque hasta el momento no haya sido tomada en cuenta.

Es sabido que la presencia de música y comedias profanas en los monasterios fue repetidamente censurada por el rey y las autoridades eclesiásticas. En 1660 Felipe IV emitió una cédula prohibiendo la representación de comedias en los monasterios de América. En 1696 el gobernador de Chile, Tomás Marín de Poveda, informó al rey que en el monasterio de agustinas el oidor de la Real Audiencia Lucas de Vivar asistía a escuchar a una monja cantora hasta las ocho o nueve de la noche, arrastrando consigo a otras autoridades y fomentando este tipo de espectáculos ${ }^{49}$. Hacia 1720 el obispo de Santiago estableció que los bailes en la clausura eran indecentes y no debían permitirse, por citar sólo tres ejemplos bien conoci$\operatorname{dos}^{50}$.

Tales prohibiciones han sido interpretadas en general de dos maneras. La historiografía tradicional las considera una consecuencia lógica de algunas conductas pecaminosas de los frailes y monjas, que las autoridades eclesiásticas y civiles estaban obligadas a corregir. La historiografía más reciente, o al menos una parte de ella, las explica por la tendencia de la autoridad eclesiástica a suprimir cualquier manifestación de raíz popular que exprese alegría o espontaneidad en beneficio de una actitud seria y contenida que representaría el ideal católico y occidental $^{51}$. El problema de ambos planteamientos es que son prácticamente idénticos entre sí, porque explican el problema a partir de un conflicto entre un poder (estatal, eclesiástico) que actúa en forma unívoca y una alteridad subalterna (llámese pueblo, monjas o frailes) que se le opone diametralmente.

Podría señalar varios argumentos en contra de estas ideas pero aquí sólo mencionaré uno al que me he referido en otro lugar. La autoridad eclesiástica nunca actuó de forma tan unívoca como han supuesto ciertos autores, primero porque existen suficientes ejemplos de eclesiásticos influyentes defendiendo -o al menos tolerando- la participación de religiosos en actividades profanas, y segundo porque el clero estaba divido en dos fragmentos -regular y secular- que tenían intereses disímiles y a veces contradictorios. Tanto es así que en 1609 el obispo de Santiago se quejó al rey de que las órdenes religiosas se estaban enriqueciendo y adquirían cada vez más tierras, con lo cual las rentas del obispado iban a menos y, si no se ponía el remedio, el obispo y miembros de la catedral andarían en pocos años "pidiendo y las religiones muy ricas" 52 . Esto se producía porque las tierras que adquirían los frailes y monjas quedaban exentas del diezmo-un diez por ciento de las ganancias en productos animales o vegetales que los propietarios debían pagar al obispado-, con lo cual la catedral se quedaba sin su principal sustento.

Ahora bien, una actividad musical de prestigio permitía a un monasterio atraer una mayor cantidad de gente. Ya decía Thomas Gage hacia 1625, a propósito de los monasterios de México: "cada iglesia tiene sus aficionados, que disputan y

\footnotetext{
${ }^{49}$ Cruz 1995: 113, 221.

${ }^{50}$ Guernica 1944: 227.

${ }^{51}$ Esta última aparece claramente representada en Salinas 2000.

${ }^{52}$ Vera 2006: 156.
} 
andan a zarpa la greña por cuál es el convento donde representan mejor, hay mejor música o visten con más gala a las niñas" 53 . A medida que aumentaba la concurrencia crecían también los ingresos procedentes de limosnas y capellanías (cantidades que los laicos legaban a alguna institución religiosa a fin de que ésta celebrara ciertas misas o alguna festividad en su nombre), lo que produjo "una guerra musical por ganarse la asistencia de público"54. Algunas capellanías, de hecho, estaban destinadas directamente a financiar la música, como aquella que fundaron entre 1673 y 1682 las hermanas Catalina, Juana, María, Isabel y Agustina Hurtado de Mendoza antes de profesar en el monasterio de agustinas ${ }^{55}$, aunque sólo fue "impuesta" por el capellán en 1748, luego de fallecer la última de ellas:

"ordenaron todas cinco fundadoras que no pasasen de trescientos pesos la renta de los aniversarios que hubiese de llevar el capellán, porque todo lo demás que sobrase aplicaron para las cantoras del coro, organista y demás instrumentarias, con el cargo de que en las misas de los jueves que se cantan en aquella iglesia se diga todo el credo en la misa de la Renovación del Santísimo Sacramento a punto de órgano [polifonía] y no en canto llano, distribuyendo el Patrón su inporte con preferencia a las más hábiles en el canto de órgano y instrumentos..." 56 .

"Si agregamos a todo lo anterior el hecho de que las catedrales hispanoamericanas estaban obligadas a dar una parte importante de sus rentas a la corona ${ }^{57}$, entonces resulta comprensible que el clero secular (obispo, prebendados) y el rey (así como sus representantes en América) aunasen fuerzas contra el clero regular (monjas y frailes), censurando algunas de sus manifestaciones musicales y artísticas que tanta gente atraían a las iglesias monásticas. Esta explicación complementa el propósito exclusivamente moralizante que sin duda tuvieron muchas de estas censuras y, sobre todo, explica la aparente contradicción que en su momento advirtió Juan Carlos Estenssoro en relación con Lima: que "las autoridades eclesiásticas mandaban a componer y hacían interpretar en la Catedral las obras que ellos mismos prohibían" en otras instituciones religiosas" 58 .

Sin embargo, si este fue el objetivo de dichas prohibiciones es dudoso que tuviesen mucho éxito, pues las fundaciones de capellanías en los monasterios santiaguinos continuaron e incluso fueron realizadas por miembros de la catedral. El secretario del cabildo y sochantre Tomás Vásquez Poyancos dejó en su testamento de 1738 veinticinco pesos anuales al mencionado monasterio de agustinas de la Limpia Concepción, de los cuales cinco debían entregarse a la vicaria

${ }^{53}$ Gage 1838: 184.

${ }^{54}$ Estenssoro 1997: 129.

${ }^{55}$ Frías 1933: 138-140. Cf. con Peña Otaegui 1951: 43.

${ }^{56}$ Archivo Nacional, Escribanos de Santiago, vol. 558, fol. 214.

${ }^{57} \mathrm{El}$ caso de la Catedral de Santiago lo demuestra claramente: una cuarta parte de sus rentas era para el obispo; otra para el cabildo; de la suma restante se dividía todo en nueve partes, de las cuales dos eran para el rey, una y media para "la Iglesia", y una y media para el hospital; las partes restantes se empleaban en pagar a los demás empleados y para cubrir otros gastos -Archivo General de Indias, Chile 63 (informe del cabildo sobre cuánto valen los frutos del obispado, ca. 1610).

${ }^{58}$ Estenssoro 1989: 87. 
de coro para que los repartiese a las cantoras y ejecutasen entre todas una solemne misa en honor de la Santísima Trinidad ${ }^{59}$. En el caso de La Victoria, sor Rosa Gutiérrez estableció en su renuncia que luego de su fallecimiento se formara una capellanía de 4000 pesos destinada a financiar el pago de cantores y otros gastos en una misa solemne que debía cantarse el primer viernes después de la octava de Corpus Christi ${ }^{60}$.

Sin duda este tipo de fundaciones, y en general la interacción entre los monasterios y su entorno urbano, son aspectos que deberán ser estudiados con detalle en el futuro. Sólo así podremos conocer o imaginar con mayor precisión la música que allí se oía, las mujeres que la interpretaban y el complejo mundo colonial en el que estaban insertas.

\section{BIBLIOGRAFÍA}

Aguirre, Soterraña

2004 "Sonidos en el silencio: Monjas y músicas en la España de 1550 a 1650", en John Griffiths y Javier Suárez-Pajares (eds.). Políticas y prácticas musicales en el mundo de Felipe II. Madrid: ICCMU, pp. 285-317.

ARNotT, W. Geoffrey

1977 "Swan Songs", Greece E Rome, 2nd Ser., XXIV/2, pp. 149-153.

BAKER, GEOFFREY

2008 Imposing Harmony. Music and Society in Colonial Cuzco. Durham, Londres: Duke University Press.

Cadenas, Viana

2002 "Música, fiestas y ceremonias en el convento de la Inmaculada Concepción de Caracas (siglos XVII-XVIII)”, en Víctor Rondón (ed.). Mujeres, negros y niños en la música y sociedad colonial iberoamericana. Santa Cruz de la Sierra: Asociación Pro Arte y Cultura, pp. 19-38.

Cano Roldán, Imelda

1981 La mujer en el reino de Chile. Santiago de Chile: Gabriel Mistral Ltda.

Claro Valdés, Samuel

1979 "Música catedralicia en Santiago durante el siglo pasado", RMCh, XXXIII/148, (octubre-diciembre), pp. 7-36.

Cruz, IsABeL

1995 La fiesta: metamorfosis de lo cotidiano. Santiago de Chile: Universidad Católica de Chile.

Estenssoro, Juan Carlos

1989 Música y sociedad coloniales. Lima 1680-1830. Lima: Colmillo Blanco.

1997 "Música y fiestas en los monasterios de monjas limeños. Siglos XVII y XVIII", Revista Musical de Venezuela, XVI/34, pp. 127-135.

\footnotetext{
${ }^{59}$ Archivo Nacional, Escribanos de Santiago, vol. 547, fol. 458.

${ }^{60} \mathrm{AMV}$, "Peticiones de religiosas de coro 1700-1799", expediente 63.
} 
FAHRENKROG, LAURA

2006 El arpa en Santiago de Chile durante la Colonia. Tesis de licenciatura. Director Alejandro Vera. Santiago: Pontificia Universidad Católica de Chile.

Frías Estanislao

1933 Capellanías, Censos y Mayorazgos, Santiago: Imp. Dirección General de Prisiones.

Gage, Thomas

1838 Nueva relación que contiene los viages de Tomas Gage en la Nueva España. Tomo 1. París: Librería de Rosa [original de 1625].

Gallardo, JUanita

2005 Confesiones de la monja alférez. Santiago de Chile: Seix Barral.

GuERnica, JuAn DE

1944 Historia y evolución del Monasterio de las Clarisas de Nuestra Señora de la Victoria en sus cuatro periodos. Santiago: Impr. Sagrado Corazón de Jesús.

Iglesias Saldaña, Margarita

1999 "El rol de las mujeres religiosas en la transmisión de la fe cristiana en la Época Colonial en Chile: una mirada a través de la vida conventual”, Revista de la Facultad de Filosofía y Humanidades, 11, en <http://www2.cyberhumanitatis.uchile.cl/ 11/index.html>.

[JEsús, Sor María Rosa DE]

1923 Recuerdos históricos del Monasterio de las Religiosas Dominicas de Sta. Rosa de Lima de Santiago de Chile. Santiago: Imprenta Lagunas y Co.

KENDRICK, RoBert L.

1996 Celestial Sirens: Nuns and Their Music in Early Modern Milan. Oxford: Clarendon Press.

Lange, Francisco Curt

1986 "Convento de San Lorenzo de Nuestra Señora de La Merced, Córdoba (Argentina)”, Latin American Music Review, VII/2, pp. 221-247.

López-Calo, José

1988 Historia de la música española. Tomo 3. Siglo XVII. Madrid: Alianza Editorial S. A.

Medina, José Toribio

1906 Diccionario biográfico colonial de Chile. Santiago de Chile: Imprenta Elzeviriana.

Peña Otaegui, Carlos

1951 Una crónica conventual. El monasterio de las agustinas de Santiago (1574-1951). Santiago de Chile: s/e.

Pereira Salas, Eugenio

1941 Los orígenes del arte musical en Chile. Santiago: Publicaciones de la Universidad de Chile, Imprenta Universitaria.

1945 "El arpa...que en dulce nota", RMCh, I/4, (agosto), p. 41.

Salinas, Cecilia

1994 Las chilenas de la colonia. Virtud sumisa, amor rebelde. Santiago de Chile: LOM Ediciones. 
Salinas, Maximiliano

2000 "¡Toquen flautas y tambores!: una historia social de la música desde las culturas populares en Chile, siglos XVI-XX”, RMCh, LIV/193 (enero-junio), pp. 45-82, disponible en <http://www.scielo.cl/scielo.php?pid=S071627902000019300003\&script=sci_arttext $>$.

SUÁREZ, ÚRSULA

1984 Relación autobiográfica. Edición de Mario Ferreccio Podestá y Armando de Ramón. Santiago de Chile: Academia Chilena de la Historia.

Vera, Alejandro

2004 "La música en el convento de La Merced de Santiago de Chile en la época colonial (s. XVII-XVIII)”, RMCh, LVIII/201 (enero-junio), pp. 34-52.

2005 "A propósito de la recepción de música y músicos extranjeros en el Chile colonial”, Cuadernos de Música Iberoamericana, 10, pp. 7-33.

2006 "Musicología, historia y nacionalismo: escritos tradicionales y nuevas perspectivas sobre la música del Chile colonial”, Acta Musicológica, LXXVIII/2, pp. 139-158.

2010 “¿Decadencia o progreso? La música del siglo XVIII y el nacionalismo decimonónico”, Latin American Music Review XXXI/1, en prensa. 


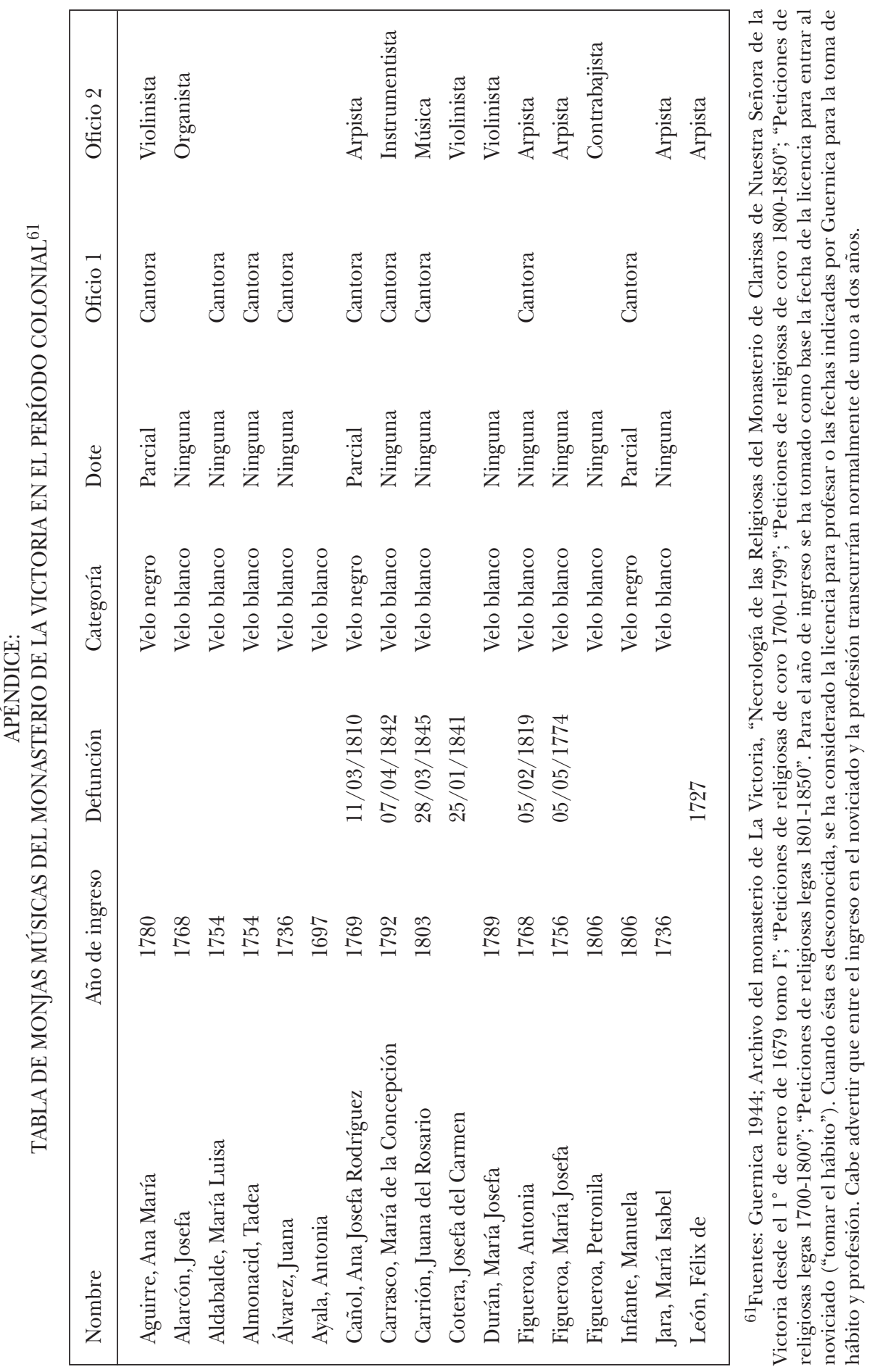




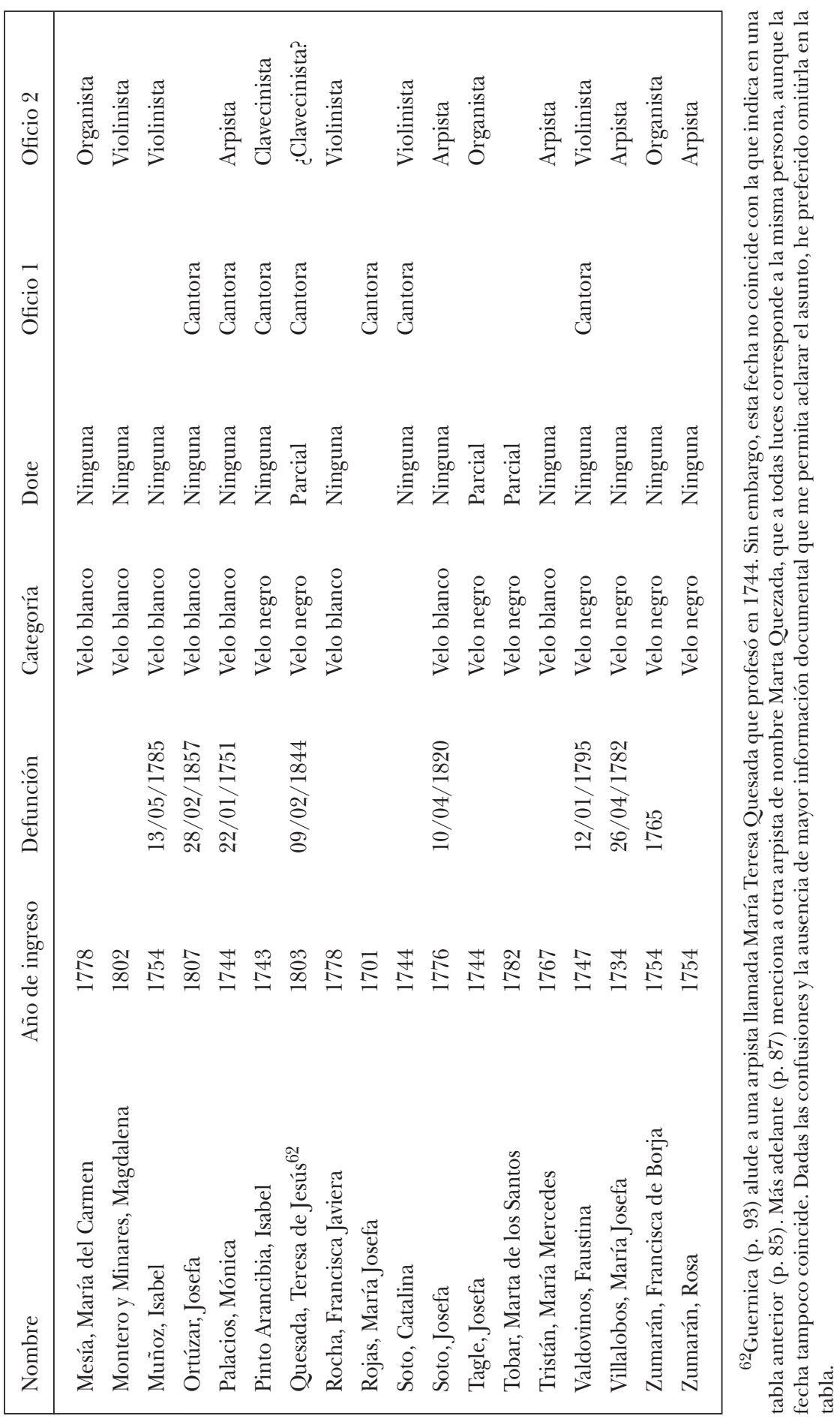

